\title{
Opća informiranost i stavovi medicinskih sestara o metodama prenatalne genetičke dijagnostike
}

\section{General awarness and attitudes of nurses about methods of prenatal genetic diagnostics}

\author{
Stella Stanojević ${ }^{1}$, Anto Čartolovni \\ 'Odjel za sestrinstvo, Hrvatsko katoličko sveučilište, llica 242, 10000 Zagreb, Hrvatska \\ 2Laboratorij za etiku digitalnih tehnologija u zdravstvu (Digit-HeaL), Hrvatsko katoličko sveučilište, Ilica 242, 10000 Zagreb, Hrvatska
}

\begin{abstract}
Sažetak
Uvod: Prenatalna genetička dijagnostika obuhvaća dijagnostičke postupke kojima ispitujemo bolesti ili patološka stanja kod ploda. Možemo ju podijeliti na dvije vrste metoda: invazivnu i neinvazivnu. S obzirom na to da invazivne metode u značajnoj mjeri mogu naštetiti i majci i plodu, posljednjih desetljeća ubrzano se razvijaju neinvazivne metode. One su sigurnije, no unatoč tome, i jedne i druge predstavljaju značajne etičke izazove. Medicinske sestre u mnogočemu mogu pridonijeti razvoju prenatalne dijagnostike putem pružanja informacija roditeljima, upoznavanja roditelja s dijagnostičkom procedurom, suosjećanja s njima, pružanjem podrške u rješavanju etičkih dilema s kojima se roditelji susreću. Cilj rada bio je ispitati i utvrditi opću informiranost medicinskih sestara o metodama prenatalne genetičke dijagnostike te ispitati stavove medicinskih sestara o njihovoj ulozi u procesu prenatalne dijagnostike.
\end{abstract}

Metode: Uzorak ispitanika činile su medicinske sestre koje rade u Kliničkom bolničkom centru Sestre milosrdnice i Općoj županijskoj bolnici Našice na Odjelu ginekologije i porodništva. U istraživanju je sudjelovalo 115 ispitanika. Korišten je upitnik koji se sastoji od 29 pitanja.

Rezultati: Ispitanici su pokazali osrednje znanje o prenatalnoj dijagnostici. Smatraju da bi trudnice trebale obavljati neinvazivne testove, da su prenatalne metode pouzdane te da medicinske sestre mogu pomoći u prihvaćanju informacije 0 anomalijama djeteta. $S$ druge strane, ispitanici se ne slažu s tvrdnjom da bi medicinske sestre trebale davati savjete trudnicama te da su invazivne metode opasne.

Rasprava: Istraživanje ukazuje na potrebu dodatne edukacije medicinskih sestara kako bi mogle djelovati na području prenatalne dijagnostike i biti uključene u genetička savjetovališta.

Zaključak: Razvojem prenatalne genetičke dijagnostike dolazi do pojave novih etičkih dvojbi koje postaju sve veći izazov medicinskim sestrama. Stoga je iznimno važno poticati obrazovanje sestara na području prenatalne genetičke dijagnostike. Uloga medicinskih sestara ne bi se smjela zadržati samo na asistirajućoj ulozi.

Ključne riječi: medicinske sestre, prenatalna genetička dijagnostika, genetičko savjetovalište, genetička informacija.

Kratak naslov: Sestrinski etički izazovi u prenatalnoj genetičkoj dijagnostici

\begin{abstract}
Introduction: Prenatal genetic diagnostics includes diagnostic procedures for examining diseases or pathological conditions of the fetus. We can divide it into two types of methods, invasive and non-invasive ones. Since invasive methods can significantly harm both mother and fetus, non-invasive methods have been developing rapidly in recent decades. As such, they are much safer, but nevertheless, they both carry considerable ethical issues. It is not enough just to make a test, but it is necessary to pay attention to all the ethical implications that it carries. In that sense, nurses can make a significant contribution. Nurses can contribute in many ways to the development of prenatal diagnostics. It can be by providing information to parents themselves, helping them understand diagnostic procedures, empathizing with them and providing support in resolving ethical dilemmas that they face.
\end{abstract}

Methods: The sample of respondents consists of nurses who work in University Hospital Center Sestre milosrdnice and General county hospital Našice at Gynecology and Obstetrics maternity hospitals. 115 respondents participated in the study. The research study uses a questionnaire with 29 questions.

Results: Subjects have mediocre knowledge of the prenatal diagnosis. They believe that pregnant women should perform non-invasive tests, that prenatal methods are reliable, and that nurses can help accept information about the child's anomalies. On the other hand, respondents disagree that nurses should give advice to pregnant women and that invasive methods are dangerous.

Discussion: The research shows that there is a need for additional education of nurses so that they can work in the field of prenatal diagnostics and be involved in genetic counseling. Besides, they should be morally aware to be able to provide valid, but also morally correct information.

Conclusion: With the development of prenatal genetic diagnostics, new ethical issues emerge and challenge more and more nurses at these wards. It is of utmost importance to encourage the education of nurses at the academic level. The role of nurses cannot and should not remain solely in the assisting role.

Keywords: nurses, prenatal genetic diagnostics, genetic counseling, genetic information

Running head: Nursing ethics challenges in the prenatal genetic diagnostics

\section{Uvod}

Prenatalna dijagnostika genetičkih poremećaja ili jednostavnije rečeno, prenatalna genetička dijagnostika potpo- dručje je kliničke genetike i perinatologije koje integrira teorijsko i kliničko znanje u medicini. Uključuje dostignuća 
u razvoju citogenetičkih, molekularno-genetičkih i molekularno-citogenetičkih metoda, a njezin je cilj što ranije i što pouzdanije dijagnosticirati različite urođene malformacije. Prenatalna genetička dijagnostika obuhvaća dvije vrste tehnika od kojih su jedne invazivne, a druge neinvazivne tehnike. Najzastupljenije su invazivne tehnike amniocenteza i biopsija korionskih resica, a neinvazivne su ultrazvuk te mjerenja razine koncentracije biokemijskih biljega. Posljednjih 20 godina radi se na razvoju neinvazivnih metoda kojima je cilj veća sigurnost za majku i plod te dostupnost što većem broju trudnica [1, 2].

Prenatalnom genetičkom dijagnostikom roditeljima se omogućava dostupnost informacija o zdravlju fetusa te o mogućim zdravstvenim teškoćama, posebice kada se radi o rizičnim trudnoćama. Roditelji imaju pravo na informaciju, a kako će tu informaciju iskoristiti, ovisi o njihovoj savjesti, vrijednostima i odgovornosti. S obzirom na to da je danas vrlo lako dijagnosticirati nasljedne bolesti prije rođenja djeteta, sasvim je legitimno pitati se koliko je etično postaviti takvu dijagnozu prije rođenja. S etičke strane gledano, najveći problem predstavljaju oni slučajevi u kojima nakon dijagnoze bolesti ili oštećenja dođe do odluke trudnice o prekidu trudnoće. Shodno tome, rasprave se najčešće svode na to bi li bilo bolje kada žena ne bi znala za dijagnozu ili kada bi tek rođenjem djeteta saznala za postojanje bolesti $[3,4,3]$.

Mnoge žene nastavljaju trudnoću unatoč spoznaji da im je dijete bolesno te su se tijekom tog razdoblja pripremale za rođenje bolesna djeteta. To je definitivna potvrda korisnosti prenatalne genetičke dijagnostike, no isto tako i potvrda da ona univerzalno ne potiče žene na prekid trudnoće. Na prenatalnu genetičku dijagnostiku treba gledati kao na pomoć ženama s rizičnom trudnoćom kako bi im se pružila informacija o tome je li njihov plod zdrav ili nije. U sklopu toga, uloge i odgovornosti medicinske sestre dobivaju na važnosti. Medicinske sestre i primalje koje rade u području ginekologije i porodništva trebale bi biti spremne pružiti odgovarajuće informacije parovima o važnosti, potencijalnim rizicima, prednostima i opasnostima prenatalne genetičke dijagnostike $[3,5,4]$.

Cilj je ovog rada ispitati i utvrditi opću informiranost sestara o metodama prenatalne genetičke dijagnostike te ispitati stavove medicinskih sestara o njihovoj ulozi u procesu prenatalne dijagnostike te povezanim etičkim problemima.

\section{Uloga i razvoj sestrinstva u prenatalnoj genetičkoj dijagnostici}

Razvoj znanja o ljudskoj genetici rapidno se proširio tijekom druge polovice prošlog stoljeća. Medicinske sestre uključene su u genetičku evaluaciju i savjetovanje obitelji, asistiranje u prikupljanju zapisa i dokumentacije, razjašnjavanje genetičkih informacija i pružanja dugotrajne asistencije. Usprkos skromnim počecima kada su medicinske sestre prikupljali povijest bolesti te pružali tek jednostavnu podršku, danas su u mogućnosti identificirati pacijentove i obiteljske rizike za pojavu različitih bolesti te ih upoznati s daljnjim mogućnostima. Navedeno je rezultat priprema putem formalne edukacije, a u zapadnim zemljama uključuje i specijalizaciju [6].
Sve veća uključenost medicinskih sestara javlja se u obliku genetičkih savjetovanja. Genetičko savjetovanje u prenatalnoj genetičkoj dijagnostici podrazumijeva savjetovanje koje se obavlja prije donošenja odluke o testiranju, ali isto tako uključuje i savjetovanje nakon samog testiranja. Prije nego što se podvrgne prenatalnoj genetičkoj dijagnostici, svaka bi trudnica trebala obaviti genetičko savjetovanje. To savjetovanje treba obaviti dovoljno rano kako bi trudnica imala dovoljno vremena za donošenje odluke hoće li se podvrgnuti testiranju ili neće. Očekivanja koja pacijenti često imaju mogu biti izrazito različita od realnih očekivanja koja postavi stručna osoba u genetičkom savjetovalištu. Upravo u tom dijelu medicinska sestra ima bitnu ulogu. Medicinske sestre moraju biti podrška roditeljima, savjetovati ih, bodriti, biti s njima u teškim, ali i sretnim trenutcima. Zbog toga valja istaknuti važnost pružanja etički ispravnih informacija, ali i pružanja jasnih informacija o njihovu zdravstvenom stanju iz medicinske perspektive putem procesa genetičkog savjetovanja. Kako bi trudnice u svakom trenutku, ali i u svakoj bolnici, imale mogućnost primanja informacija koje su točne i valjane, ističe se nužnost otvaranja genetičkih savjetovališta u svakoj bolnici u kojoj se obavlja prenatalna genetička dijagnostika. Slijedom navedenog, potrebno je staviti naglasak na obrazovanje medicinskih sestara u ovome području kako bi budući roditelji uvijek i u svakoj zdravstvenoj ustanovi mogli dobiti informaciju o prenatalnoj dijagnostici $[7,8]$.

\section{Materijali i metode}

Istraživanje je provedeno na uzorku od 115 medicinskih sestara na Odjelima ginekologije i porodništva Kliničkog bolničkog centra (KBC) Sestre milosrdnice i Opće županijske bolnice (OŽB) Našice. Za potrebe istraživanja sastavljen je upitnik od 29 pitanja podijeljenih u dva dijela: prvi se sastojao od sociodemografskih pitanja, a drugi se dio usmjerio na pitanja kojima je cilj bio ispitati znanje i stavove o postupcima prenatalne genetičke dijagnostike. Odgovori na pitanja iz prvog dijela bili su izraženi na nominalnoj mjernoj ljestvici, dok su odgovori na pitanja iz drugog dijela prikupljeni Likertovom ljestvicom. Za ocjenu značajnosti dobivenih rezultata korištena je razina značajnosti $5 \%$, a za obradu podataka program IBM SPSS Statistics 20. Istraživanje je odobrilo Etičko povjerenstvo KBC-a Sestre milosrdnice i Etičko povjerenstvo OŽB-a Našice.

\section{Rezultati}

U istraživanju je sudjelovalo 115 ispitanika, od čega je 6 (5,2 \%) muškaraca i 109 (94,8 \%) žena. Razlika je u spolu značajna te ih zbog toga nije bilo moguće statistički uspoređivati. Prigodnim uzorkom medicinskih sestara / tehničara obuhvaćeno je $66(57,4 \%)$ ispitanika iz KBC-a Sestre milosrdnice, a iz OŽB-a Našice 49 (42,6 \%) sudionika. Dobna struktura pokazuje da većina ispitanika, njih 40 (34,8\%), ima između 18 i 29 godina, a 38 ispitanika (33\%) ima 50 ili više godina. Najviše ispitanika, njih 73 (63,7 \%), radilo je na Odjelu ginekologije i porodništva, dok su ostali radili u ambulanti, rađaonici i Zavodu za neonatologiju i intenzivno liječenje. Prema razini obrazovanja najviše ispitanika imalo je srednju stručnu spremu, njih 78 (68,4\%). 
Znanje ispitanika o metodama prenatalne dijagnostike ukazuje na to da je većina ispitanika, njih 103 (89,6\%), upoznata s tehnikama prenatalne dijagnostike. Najzastupljenije su tehnike u njihovim odgovorima Ultrazvuk (UZV), triple test, Harmony Prenatal test i kordocenteza. Ispitanici su pitani o razlikovanju bioloških pojmova kao što su genotip i fenotip, a od svih ispitanika samo četirima ispitanicima $(3,6$ \%) nije bila poznata razlika.

Osim poznavanja metoda, željelo se ispitati vlastito iskustvo ispitanika, odnosno jesu li ikada napravili prenatalne genetičke testove u trudnoći. Većina ispitanika, ukupno 49 (70 \%), navelo je da nisu radili prenatalne genetičke testove u trudnoći, dok 21 (30\%) ispitanik navodi da je to učinio. Ispitanici koji su se podvrgnuli prenatalnim genetičkim testovima uglavnom dolaze iz Zagreba. S druge strane, željelo se ispitati razmišljaju li ispitanici o obavljanju nekih od prenatalnih genetičkih testova u budućnosti. Njih 51 $(44,3 \%)$ navodi da bi razmislio, 25 (21,75 \%) navodi kako ne bi, dok njih 39 (33,9 \%) navodi da ne zna. Ispitanici koji bi razmislili o radu prenatalnih genetičkih testova uglavnom dolaze iz Zagreba.

Podaci prikupljeni Likertovom ljestvicom ispitivali su slaganje s mišljenjima i postupcima medicinskih sestara o prenatalnoj genetičkoj dijagnostici. Ispitanici su se u prosjeku najviše slagali s tvrdnjama: svaka trudnica trebala bi obavljati neinvazivne prenatalne genetičke testove $(M=3,75$; SD $=1,39$ ), metode prenatalne genetičke dijagnostike pouzdane su $(M=3,68 ; S D=0,86)$, medicinske sestre trebaju biti uz osobu kada primi informaciju o mogućem riziku od kromosomske anomalije $(M=3,94 ; S D=1,15)$ te medicinske sestre mogu pomoći u prihvaćanju informacija vezanih za kromosomske anomalije i donošenju odluka $(M=3,71$; $S D=1,16)$. $\mathrm{S}$ druge strane, ispitanici su se u prosjeku najmanje slagali s tvrdnjama: medicinske sestre trebale bi davati savjete o daljnjim mogućnostima ako trudnica dobije nalaz koji pokazuje rizik od nastanka kromosomske anomalije $(M=1,90$; $S D=1,49)$ te da bi svaka trudnica trebala obaviti invazivne prenatalne genetičke testove $(M=2,30 ; S D=1,14)$. Usporede li se gradovi, ispitanici iz Zagreba najviše su se slagali s tvrdnjom da bi prenatalnu genetičku dijagnostiku trebale obavljati samo trudnice starije od 35 godina ili s povećanim rizikom ( $\mathrm{t}=2,493 ; \mathrm{p}=.014$ ), dok su ispitanici u Našicama navodili da medicinske sestre trebaju davati savjete o daljnjim mogućnostima trudnicama kod kojih postoji rizik od nastanka kromosomskih anomalija $(t=2,083 ; p=.040)$.

Od ukupnog broja ispitanika, 41 ispitanik (36,28 \%) koji je svjedočio odluci o prekidu trudnoće nakon nalaza koji su pokazivali anomaliju, navodi da su trudnice tražile dodatne informacije ( $t=2,243 ; p=.027)$, a njih $13(31,7 \%)$ se slagalo s tvrdnjom da bi odluka trudnice možda bila drugačija da je dobila bolje i detaljnije informacije.

Na tragu pružanja odgovarajućih rješenja i bolje pripreme roditelja, željela se ispitati percepcija medicinskih sestara o potrebi otvaranja genetičkih savjetovališta. Najveći broj ispitanika, njih $48(41,7 \%)$ nije bilo sigurno što misli o tome, dok $46(40,4 \%)$ ispitanih tvrdilo je kako bi otvaranje genetičkih savjetovališta u kojima rade medicinske sestre imalo pozitivan učinak na cjelokupan proces prenatalne dijagnostike. Usporede li se gradovi, ispitanici iz Našica, njih
$26(53,1 \%)$, smatraju da bi otvaranje genetičkih savjetovališta u kojima rade medicinske sestre imalo pozitivan učinak, dok samo 20 (30,8 \%) ispitanika iz Zagreba smatra isto.

\section{Rasprava}

Struktura zaposlenih medicinskih sestara u Hrvatskoj pokazuje da najveći broj medicinskih sestara ima srednju stručnu spremu. Medicinske sestre moraju biti upoznate s metodama prenatalne genetičke dijagnostike, moraju poznavati bit i problematiku kako bi se mogle upustiti u raspravu s roditeljima te kako bi ih mogle kvalitetno i dostatno educirati. $U$ istraživanju na tu temu navodi se da samo kliničke sestre s razvojnim kompetencijama i završenim diplomskim studijem mogu djelovati samostalno u navedenom području rada. Istraživanje provedeno u Turskoj pokazuje kako medicinske sestre nemaju dostatno znanje o genetici. Nužno je obrazovanje medicinskih sestara koje bi se odnosilo na prenatalnu sestrinsku skrb kako bi se mogle prepoznati potrebe za pružanjem usluga prenatalne dijagnostike. $[9,10]$.

Metode prenatalne dijagnostike svakim danom sve više napreduju, no usprkos tom napretku, medicinske sestre nisu dovoljno spremne za njihovo provođenje. Razlozi zbog kojih je situacija takva mogu biti sljedeći: nedostatno obrazovanje, određen postotak rizika koji ima prenatalna dijagnostika, neiskustvo, predrasude, etičke dileme i slično.

Početkom 1970-ih godina dolazi do značajnog razvoja neinvazivne dijagnostike. Studija iz Japana pokazuje kako većina trudnica i zdravstvenih djelatnika ima pozitivan stav prema neinvazivnim metodama prenatalne dijagnostike. Ti pozitivni stavovi doprinose prihvaćanju neinvazivnih metoda prenatalne dijagnostike u kliničkoj praksi. Ipak, postoje razlike između očekivanja i indikacija između zdravstvenih djelatnika i trudnica po pitanju neinvazivnih tehnika. Trudnice očekuju sigurnost i manji stres, a zdravstveni djelatnici veću dijagnostičku točnost i uspostavljanje konačne dijagnoze [11, 3, 12]. Istraživanje provedeno u sklopu ovog rada govori kako se medicinske sestre u velikom stupnju slažu da bi svaka trudnica trebala obaviti neinvazivnu prenatalnu dijagnostiku. No, postavlja se pitanje zašto medicinske sestre smatraju da trudnice trebaju obavljati neinvazivne prenatalne testove ako one same nisu to činile ili ne razmišljaju o tome da to učine.

Invazivne metode prenatalne dijagnostike predstavljaju opasnost od pobačaja ili povrede fetusa, a koriste se kod žena koje su starije od 35 godina, imaju povijest obiteljske bolesti ili sumnju na poremećaj. U istraživanju provedenom u sklopu ovog rada ispitanici su se u velikom stupnju složili da trudnice ne bi trebale obavljati invazivne testove. U istraživanju iskustva o prenatalnom genetičkom probiru i dijagnostičkom testiranju među korejskim trudnicama u poodmakloj životnoj dobi navodi se kako se invazivne dijagnostičke procedure i dalje smatraju značajnim dijagnostičkim testovima te imaju važnu ulogu u praksi. Nadalje, međunarodna studija u Hong Kongu i Japanu pokazuje različite rezultate po pitanju preferencija neinvazivnih prenatalnih testova i podvrgavanja amniocentezi za postavljanje dijagnoze. Trudnice su u navedenom istraživanju bile podvrgnute amniocentezi. Tijekom razdoblja čekanja navode 
kako su bile neinformirane, osjećale su određen stupanj tjeskobe zbog ishoda testa te su se osjećale manje vrijednima zbog mogućih poremećaja kod ploda. Nakon dobivanja rezultata testa nije im bilo jasno zašto se provodi takva vrsta testiranja ako pobačaj zakonski nije moguć te ne vide svrhu u tome $[13,14]$.

Ističe se iznimna važnost uloge medicinskih sestara u pružanju pravovaljanih informacija glede upoznavanja s postupkom provođenja prenatalne dijagnostike i upoznavanja s njezinim rezultatima. U tom cjelokupnom procesu posebice se ističe njihova savjetodavna uloga. Dobrim informiranjem trebalo bi pomoći pri donošenju ispravne odluke, no ako osoba ipak inzistira, potrebno je dodatno educirati pacijenticu o posljedicama pobačaja i pozitivnim aspektima djetetova rađanja [5]. U prvi plan treba staviti pomaganje roditeljima u prihvaćanju dijagnoze djeteta te ukazati na pozitivne i negativne aspekte njihove odluke. $U$ takvoj složenoj situaciji i procesu donošenja odluka, roditeljski svjetonazor ne smije biti isključen faktor. $U$ istraživanju provedenom u sklopu ovog rada pokazuje se velik stupanj slaganja sestara s tvrdnjom da bi one trebale biti uz osobu kada dobije informaciju o mogućem riziku od kromosomske anomalije, ali i o načinima pomoći roditeljima u prihvaćanju te informacije. Međutim, daljnjom analizom ispitanici pokazuju da se ne slažu s tvrdnjom da bi medicinske sestre trebale davati savjete o daljnjim mogućnostima kod nalaza koji pokazuju povećan rizik. Iz toga se može zaključiti da je savjetodavna uloga medicinskih sestara više zastupljena u smislu podrške nego davanja savjeta o daljnjem postupanju.

Mali broj medicinskih sestara uključen je u genetička savjetovališta kao njihovo primarno mjesto rada. Budući da medicinske sestre imaju potrebna znanja i vještine za kompetentno obavljanje savjetodavne funkcije, genetičko savjetovanje pokazuje se kao primjereno sestrinskoj ulozi. lako postoji potreba za uključivanjem sestara u genetička savjetovališta, njihova uloga u tom području ipak nije jasno definirana niti potpuno razvijena [15]. U istraživanju provedenom u sklopu ovog rada pokazano je da medicinske sestre nisu sigurne o potrebi otvaranja takvih savjetovališta. Razlozi mogu biti višestruki: nedostatak kompetencija, znanja, strah zbog samostalnog djelovanja, neiskustvo, njihovi svjetonazori, etičke dileme i slično. Da bi se točno utvrdilo koji su razlozi takvih stavova, potrebno je provesti istraživanja na tu temu.

\section{Zaključak}

Razvojem prenatalne genetičke dijagnostike dolazi do pojave novih etičkih dvojbi koje postaju sve veći izazov medicinskim sestrama. Razvojem znanosti, a time i medicine, te povećanjem socijalnih, etičkih, ali i međuljudskih standarda, uloga medicinskih sestara ne može se i ne smije se zadržati samo na pomagačkoj i asistirajućoj ulozi. Potrebno je razvijati samostalnost u smislu savjetodavne uloge te direktne podrške budućim roditeljima.

\section{Nema sukoba interesa}

Authors declare no conflict of interest

\section{Literatura/References}

[1] Wieacker P, Steinhard J. The Prenatal Diagnosis of Genetic Diseases. Deutsches Aerzteblatt International. 2010;107(48): 857-62.

[2] Kešina I. Etičko-moralni vidici ljudskog nastajanja (II). Crkva u svijetu. 1996;31(3):275-90.

[3] Zergollern-Čupak Lj. Bioetika i medicina. Zagreb: Pergamena: 2006.

[4] Kešina I. Etičko-moralni vidici ljudskog nastajanja (II). Crkva u svijetu. 1996;31(3):275-90.

[5] Utkualp N, Jildiz H. Nurses' Attiudes towards Prenatal Diagnostic Procedures within Ethical Considerations. International Journal of Caring Sciences. 2016;9:380.

[6] Forsman I. Evolution of the Nursing Role in Genetics. Journal of Obstetric Gynecologic \& Neonatal Nursing. 1994;23: 481-86.

[7] Begić MA, Turi A. Prenatalna dijagnostika i moralne implikacije. Obnovljeni život. 2018;73(2):239-50.

[8] Clarke AJ, Wallgren-Pettersson C. Ethics in genetic counselling. Journal of Community Genetics. 2018;10(1):3-33.

[9] Greco KE, Tinley S, Seibert D. Development of the Essential Genetic and Genomic Competencies for Nurses With Graduate Degrees. Annual Review of Nursing Research. 2011;29(1): 173-90.

[10] Seven M, Eroglu K, Akyuz A, Ingvoldstad C. Educational needs of nurses to provide genetic services in prenatal care: A cross-sectional study from Turkey. Nurs Health Sci.

[11] Wagner J. Neinvazivno prenatalno testiranje (NIPT). Paediatria Croatica. 2016;60(1): 46-52. 2017;19(3):294-300.

[12] Yotsumoto J, Sekizawa A, Koide K, i sur. Attitudes toward non-invasive prenatal diagnosis among pregnant women and health professionals in Japan. Prenat Diagn. 2012;32(7):674-79.

[13] Čulić V, Pavelić J, Radman M. Genetičko informiranje u praksi. Zagreb, Medicinska naklada; 2016.

[14] Jun M, Thongpiwan V, Choi KS. Experiences of Prenatal Genetic Screening and Diagnostic Testing Among Pregnant Korean Women of Advanced Maternal Age. J Transcult Nurs. 2017;28(6):550-7.

[15] LaRochelle D. Prenatal genetic conselling:ethical and legal interfaces with the nurse's role. Issues Health Care Women. 1983;4(1):77-92. 


\section{Prilog [1] Anketni upitnik}

Upute: Molimo vas odgovorite na par demografskih pitanja o sebi. Ove informacije će nam pomoći kako bi opisali karakteristike medicinskih sestara/tehničara koji sudjeluju u ovom istraživanju. Molimo vas odgovorite na sva pitanja.

\section{Spol:}

a) žensko

b) muško

\section{Područje rada:}

a) Zagreb

b) Našice

\section{Dob:}

a) 18 - 29 godina

b) 30 - 39 godina

c) 40 - 49 godina

d) 50 i više godina

\section{Radni staž u sestrinstvu:}

a) 0 - 10 godina

b) 11 - 20 godina

c) 21 - 30 godina

d) 31 i više godina

\section{Radno mjesto:}

a) Odjel

b) Ambulanta

c) Operacijska sala

d) Drugo

\section{Završeni stupanj obrazovanja:}

a) SSS (med. sestra)

b) VŠS (bacc. med. techn)

c) VSS (dipl. med. techn/mag. med. techn) d.

\section{Bračni status:}
a) U braku
b) Izvanbračna zajednica
c) Samac

8. Imate li djece:

a) Da, imam

b) $\mathrm{Ne}$, nemam

9. Znate li razliku između genotipa i fenotipa?

a) Da, znam

b) $\mathrm{Ne}$, ne znam
10. Koje sve tehnike prenatalne dijagnostike poznajete?

11. Da li ste Vi ili Vaša partnerica za vrijeme trudnoće radili prenatalne genetičke testove?
a) Da, jesmo
b) $\mathrm{Ne}$, nismo
c) Nemam djece

\section{Da li biste razmislili raditi prenatalni genetički test $u$} trudnoći?
a) Da, bih
b) $\mathrm{Ne}$, ne bih
c) Ne znam

13. Da li ste svjedočili odluci i namjernom prekidu trudnoće nakon nalaza koji je pokazao kromosomske anomalije?
a) $\mathrm{Da}$, jesam
b) $\mathrm{Ne}$, nisam

14. Smatrate li da bi odluka trudnice bila drugačija da je dobila bolje, detaljnije informacije?
a) Da, smatram
b) $\mathrm{Ne}$, ne smatram
c) Možda bi postupila drugačije
d) Nisam siguranjna

15. Vidite li potrebu za otvaranjem genetičkih savjetovališta u kojima bi radile medicinske sestre/tehničari?
a) Da, vidim potrebu
b) $\mathrm{Ne}$, ne vidim potrebu
c) Nisam siguran a

16. Smatrate li da bi otvaranje genetičkih savjetovališta u kojima rade medicinske sestre/tehničari imalo pozitivan učinak na cjelokupni proces prenatalne dijagnostike?
a) Da, smatram
b) $\mathrm{Ne}$, ne smatram
c) Nisam siguran/a

17. Ukoliko Zelite nešto nadopuniti, ada to pitanja nisu pokrila, molim Vas da navedete ispod. 
Upute: U sljedećem dijelu ankete molim Vas na postavljena pi tanja odgovorite ponuđenom Likertovom skalom od 1 do 5. Značenje brojeva: 1 - potpuno se slažem; 2 - uglavnom se slažem; 3 - ne mogu se odlučiti; 4 - uglavnom se ne slažem; 5 -uopće se ne slažem. Molimo Vas odgovorite na sva pitanja.

\begin{tabular}{|c|c|c|c|c|c|c|}
\hline & & $\begin{array}{l}\text { Potpuno } \\
\text { se slažem }\end{array}$ & $\begin{array}{l}\text { Uglavnom } \\
\text { se slažem }\end{array}$ & $\begin{array}{l}\text { Ne mogu } \\
\text { se odlučiti }\end{array}$ & $\begin{array}{l}\text { Uglavnom se } \\
\text { ne slažem }\end{array}$ & $\begin{array}{l}\text { Uopće se } \\
\text { ne slažem }\end{array}$ \\
\hline 1. & $\begin{array}{l}\text { Slažete li se da bi svaka trudnica trebala } \\
\text { obaviti neinvanzivne prenatalne genetičke } \\
\text { testove (npr. Triple test ili Doppler)? }\end{array}$ & 1 & 2 & 3 & 4 & 5 \\
\hline 2. & $\begin{array}{l}\text { Slažete li se kako svaka trudnica treba } \\
\text { obaviti invanzivne prenatalne genetičke } \\
\text { testove (aminocinteza, biopsija, kordocenteza)? }\end{array}$ & 1 & 2 & 3 & 4 & 5 \\
\hline 3. & $\begin{array}{l}\text { Slažete li se da prenatalnu genetičku } \\
\text { dijagnostiku trebaju obavljati samo trudnice } \\
\text { starije od } 35 \text { godina iii sa povećanim } \\
\text { rizikom od razvoja anomalija? }\end{array}$ & 1 & 2 & 3 & 4 & 5 \\
\hline 4. & $\begin{array}{l}\text { Slažete li se da su metode prenatalne } \\
\text { genetičke dijagnostike pouzdane metode? }\end{array}$ & 1 & 2 & 3 & 4 & 5 \\
\hline 5. & $\begin{array}{l}\text { Slažete li se da trudnice dobivaju dostatne } \\
\text { usmene i pismene informacije o važnosti i } \\
\text { rizicima pojedine pretrage? }\end{array}$ & 1 & 2 & 3 & 4 & 5 \\
\hline 6. & $\begin{array}{l}\text { Trudnice često traže dodatne informacije } \\
\text { od mene o prenatalnoj dijagnostici? }\end{array}$ & 1 & 2 & 3 & 4 & 5 \\
\hline 7. & $\begin{array}{l}\text { Slažete li se da bi Vi kao zdravstveni } \\
\text { djelatnik trebali davati informacije o } \\
\text { prenatalnoj dijagnostici? }\end{array}$ & 1 & 2 & 3 & 4 & 5 \\
\hline 8. & Zašto? (molim napisati) & & & & & \\
\hline 9. & $\begin{array}{l}\text { Slažete li se da imate moralnu obvezu im } \\
\text { odgovoriti iako nije u vašoj profesionalnoj } \\
\text { domeni? }\end{array}$ & 1 & 2 & 3 & 4 & 5 \\
\hline 10. & $\begin{array}{l}\text { Ukoliko trudnica dobije nalaz koji pokazuje } \\
\text { rizik od nastanka kromosomske anomalije, } \\
\text { slažete li se da bi medicinska sestra trebala } \\
\text { davati savjete o daljnjim mogućnostima? }\end{array}$ & 1 & 2 & 3 & 4 & 5 \\
\hline 11. & $\begin{array}{l}\text { Slažete li se da bi medicinske sestre/tehničari } \\
\text { trebali biti uz osobu kada zaprimi jednu } \\
\text { takvu informaciju? }\end{array}$ & 1 & 2 & 3 & 4 & 5 \\
\hline 12. & $\begin{array}{l}\text { Slažete li se da medicinske sestre/tehničari } \\
\text { mogu pomoći osobi da prihvati takvu } \\
\text { informaciju i danese odluku? }\end{array}$ & 1 & 2 & 3 & 4 & 5 \\
\hline
\end{tabular}

